\title{
DIGITAL MARKETING REGULATIONS
}

\author{
R.-M. URZICEANU, V.-S. PAŞCALĂU
}

\section{RAMONA-MIHAELA URZICEANU}

Agora University, No. 8 Tineretului, Oradea, Romania

ramona.urziceanu@gmail.com

\section{VALENTINA-SIMONA PAŞCALĂU}

Agora University, No. 8 Tineretului, Oradea, Romania

simona.pascalau@univagora.ro; valentina.pascalau73@e-uvt.ro

\section{ABSTRACT}

The General Data Protection Regulation (GDPR) is a European law which grants rights regarding an individual's personal data. Having been adopted in April 2016, its enforcement became effective as of $25^{\text {th }}$ May 2018.

This article aims to highlight who should do this, what exactly they should do and how to do it. Learn about the scope of GDPR in digital marketing, the definition of a personal data breach, the rights of data subjects, incident response under GDPR and more.

KEYWORDS: digital marketing, relational marketing, online advertising, consumer rights, GDPR

\section{INTRODUCTION}

Over the last two decades, we have witnessed a true explosion of marketing research with regard to the impact of the Internet and of related technologies on consumers and on the way in which markets operate. The increase in the level of knowledge held by consumers, access to information, and instant communication are also factors that result in an almost total transparency of companies' offerings at global level. The developments observed in the marketing literature regard the emphasis placed on the analysis of internet surfing behaviours nd the peculiarities of computer-mediated environments (CME) (MacInnis, 2011 ${ }^{1}$; Yadav, 2010). ${ }^{2}$

The concept of "digital marketing" is different from the concept of "marketing" (American Marketing Association), being considered not as a subcategory of classical marketing, but as a separate branch. There are four key interactions in the digital environment: consumer-company interactions, company-consumer interactions, consumerconsumer interactions, and company-company interactions (Yadav \& Pavlou 2014) ${ }^{3}$. The research of consumer-company interactions focuses on consumer behaviour in the context of interacting with companies in the digital environment. Research on company-consumer interactions focuses on the strategies and tactics of companies that interact with consumers in the digital environment.

\footnotetext{
${ }^{1}$ MacInnis , D. J. , (2011), A Framework for Conceptual Contributions in Marketing, Journal of Marketing

${ }^{2}$ Yadav M.S., (2010), Marketing in Computer-Mediated Environments: Research Synthesis and New Directions , Journal of Marketing

${ }^{3}$ Yadav, M.S., Pavlou, P.A. , (2014), Marketing in Computer-Mediated Environments: Research Synthesis and New Directions , Journal of Marketing
} 
CONSIDERATIONS IN REGARDS TO THE PROTECTION OF PERSONAL RIGHTS

GRANTED AFTER THE PERSON'S DEATH

Research on consumer-consumer interactions consists in the analysis of the behaviour of consumers who interact with other consumers in the digital environment. Research on company-company interaction focuses on a company's strategies and tactics in the context of interacting with other companies in the digital environment.

\section{DIGITAL MARKETING AND RELATIONAL MARKETING}

There is a general consensus that digital environments have had a significant impact on the manner in which a trader reaches the consumer at present.

Digital media refers to electronic media that disseminate information in digital formats.

This includes any media available by means of your computer, smartphones, or other digital devices.

The Internet is a prominent place of digital marketing and online advertising is a form of promotion that uses the Internet for the explicit purpose of transmitting marketing messages.

The Internet has become the fastest means of advertising of this decade. Advertising agencies spend hundreds of millions of dollars to place their ads on high traffic websites. According to research, when people read online advertising, they are more likely to purchase online. An advertising banner on the Internet might balance the playing field between large and small companies (Smith, 2009). ${ }^{4}$

The increase in online advertising is in response to the growth in the number of consumers who use the Internet to buy and sell goods and services. Such exchange of goods is referred to as electronic commerce or e-commerce.

In a report on e-commerce drawn up by the Organization for Economic Cooperation and Development (OECD), the financial crisis which began in 2008 has stimulated global ecommerce sales, as consumers have looked for ways to reduce spendind. E-commerce is expected to grow in the US, and in Europe and developing countries the growth will be even faster (Schulman, 2008). The annual growth of e-commerce is expected to increase to $28 \%$, while certain individual countries have even higher growth rates. In India, for example, the growth rate of e-commerce was estimated at $51 \%$ per annum (Marvist Consulting, 2008).

Online reviews are a way to personalize a relationship and they range from personal reviews from other customers to personalized recommendations provided by engines or referral systems.

Recommended systems are sources of information that provide consumers with personalized information (Ansari, Essegaier, \& Kohli, 2000). ${ }^{5}$

Such systems use an information filtering technique in order to formulate product recommendations that are most likely to be of interest to the user.

Traders will benefit from recommendations addressed to online consumers, especially if the source concerned provides personalized recommendations.

Consumers focus more on the source of the recommendation than on the type of website on which the recommendation appears (Senecal \& Nantel, 2004). ${ }^{6}$

\footnotetext{
${ }^{4}$ Smith, T. , (2009) , Marketing communications: A brand narrative approach

${ }^{5}$ Ansari, A., Essegaier , S. , Kohli, R. , Internet Recommendation Systems, Journal of Marketing Research
} 
Consumers' online reviews provide a source of reliable information for consumers and, therefore, a valuable potential for sales.

Since online peer reviews can be very beneficial to a company, traders should determine what motivates consumers to write such reviews.

Consumer-generated ads, podcasts, and blogs are on the increase with the help of websites such as YouTube, V-Cam and Google Video.

Companies are becoming interested in the mobility of consumer-generated content as a digital marketing tool.

Organizations are proactively trying to induce consumers to spread the word about their products (Godes et al., 2005) ${ }^{7}$. Providing consumers with a place of affirmation has become a business in itself. In return for consumer-generated content, certain organizations pay money, grant points, or offer some other form of acknowledgement (Chatterjee, 2001) so we may be speaking of relational marketing.

Relational marketing means a strategy for selecting and maintaining clients; it involves a business philosophy that puts the client at the centre of attention throughout all processes; success is possible only if there is a leading team, suitable organizational strategies and culture acting simultaneously.

It is also a process of implementation of a strategy that puts the client at the centre of attention, which, as in a "chain reaction", determines the redefining of all functional activities, thus involving new work processes that are only possible by using information technology.

Relational marketing may be considered an extension of the concept of service provision to a continuous process that is, at once, an art and a science consisting of the collection and use of information about the client, in order to induce a certain degree of fidelity in the latter and a process of orientation of the entire company outwards, towards clients, which presupposes an understading of clients' needs and conducting processes within the company so as to develop and maintain relationships with clients that would turn them into permanent clients.

The goals of relational marketing are to attract, satisfy, retain and improve the relationship with consumers.

In order for these goals to be achieved in optimal conditions, a privacy policy must be put in place, and organizations have the interest of keeping their website and clients' financial information secured, and this is where the General Data Protection Regulation (GDPR) intervenes.

\section{UNDERSTANDING GDPR AND ITS IMPACT}

The General Data Protection Regulation (GDPR) is a new privacy-protection regulation which became active and applicable as of May 2018. It was initiated by the European Union, but has an enormous impact on traders around the world.

The term "personal data" is the access way to the enforcement of the General Data Protection Regulation (GDPR). The General Data Protection Regulation applies only if data processing relates to personal data. The term is defined in Article 4(1)(1). Personal data is any information that is related to an identified or identifiable individual.

In fact, such fines may be up to $4 \%$ of the annual global turnover or 20 million euros, whichever of the two is greater. GDPR defines personal data to a great extent. A very large number of marketing users are used in order to provide the working definitions of PII or

\footnotetext{
${ }^{6}$ Senecal, S. and Nantel, J. (2004) The Influence of Online Product Recommendations on Consumers' Online Choices. Journal of Retailing

${ }^{7}$ Godes, D. , ( 2005) , The Firm's Management of Social Interactions, Marketing Letters

${ }^{8}$ Chatterjee, P. (2001), Online Re views - Do Consumers Use Them?, ACR 2001 Proceedings
} 
GRANTED AFTER THE PERSON'S DEATH

Personally Identifiable Information. PII is not the same as personal data. GDPR expands the definition of personal data in order to include certain quite common non-PII items, such as anonymous IDs and cookies.

So, wherever you are, if you simply have a website that could be accessed by someone from within the European Union, or if you have a web analytics tool or a modern tracking tool installed, GDPR applies to you, too. If this comes as a shock, you are not alone. Forester predicted that $80 \%$ of all companies would not comply with the GDPR in 2018. And, since this has technically been the law for over two years, before the date of implementation, any period of grace or leniency is hard to justify.

As a marketer in today's reality, the simple fact is that you collect, store and use personal data as a matter of course. GDPR means that you will need to take additional steps to ensure compliance, especially when it comes to any of you interacting with an EU country. And while the GDPR is there to protect European residents currently, other regions of the world are developing their own rules and regulations which are likely to adopt many of the same provisions. ${ }^{9}$

A lot of people see this as a wake-up call urging them to adopt a conservative approach that will help protect them to a greater extent in the future. Keep in mind that GDPR also applies to all your suppliers and technology partners. If you use almost any digital marketing technology anywhere in the marketing or advertising stacks that allow for digital ad targeting, for example, you will be responsible for ensuring that your personal data is compliant, as it flows from one system to another and from one seller to another.

The General Data Protection Regulation (GDPR) imposes new rules on EU organizations and on those that offer goods and services or that collect and analyze data related to persons present on the territory of the EU, regardless of their geographical location.

The major changes brought about by GDPR in digital marketing regard personal privacy, control and notifications, transparent policies and training.

Personal privacy is imperative, so individuals have the right to access their personal data, to correct personal data errors, to delete personal data, to oppose personal data processing, and to export personal data.

As far as control and notifications are concerned, organizations will have to: protect personal data by using the necessary security, notify authorities about any personal data compromise, obtain the consent for data processing, and preserve the details of any personal data processing - transparent policies.

On the other hand, organizations are required to: provide details that are relevant to data collection, detail the processing needs, define data retention and deletion policies.

Organizations must resort to training in order to educate people how to deal with privacy issues and to educate employees, audit and update data policies, hire a Data Protection Officer (if necessary), and create and manage contracts with vendors that are aligned with the GDPR.

All companies, whether large or small, which collect data will have the obligation to comply with the GDPR. They will have to inform consumers whenever they want to collect data and get their explicit consent in this respect and, if their data policy changes in any way, the process must start all over again and the consent must be renewed.

\footnotetext{
${ }^{9}$ https://gdpr-info.eu/issues/personal-data/
} 
Therefore, any organization must request consent, which means that:

$>$ it has verified that consent is the best legal way to allow the processing

$>\quad$ it has made the request for consent separately from the terms and conditions

$>\quad$ it has asked users to explicitly opt-in

$>$ it has not used pre-ticked boxes or another type of default consent

$>$ it uses language which is clear, simple and easy to understand

$>$ it specifies why it wants the data and what the data will be used for

$>\quad$ it offers granular consent options for independent processing operations

$>$ it clearly names organizations and possible third parties

$>$ it tells users that they can withdraw their consent

$>$ it ensures that users can refuse to give their consent

$>$ it does not use consent as a prerequisite for providing the service

$>$ if it offers online services directly to children, it must seek to obtain consent only if it has an age verification system and a way to obtain parental consent.

After the request, the organization registers the consents by:

$>$ keeping records of consents - when, where, who gave the consent

$>$ keeping records of all things communicated to the users at the time of obtaining the consents.

The security and privacy of information is important, clients expect that if they provide detailed personal information and financial information, it should be safely stored, therefore, organizations are required to:

$>$ regularly verify consents to ensure that the relationship, the processing and the goals have not changed in the meantime

$>$ have well-defined processes in order to refresh the consents if needed, including for parental consents

$>$ create some privacy dashboards, if needed

$>$ facilitate the method for users to withdraw their consent at any time, and communicate such method

$>$ act according to requests for withdrawal of consent as soon as possible

$>$ not sanction users who wish to withdraw their consent.

\section{CONCLUSIONS}

Digital technologies are quickly changing the environment in which businesses operate. Digital technologies reduce asymmetries between clients and sellers in significant ways. The analysis of interactions between digital technologies and environmental elements begins by examining how consumer behaviour changes as a result of gaining access to a variety of technologies and devices, both in online and mobile contexts. We focus on how this affects the acquisition of information in terms of quality and price, the search process, the expectations of clients and the implications concerning them.

In the same way, companies have to deal with search engines as collaborators and platforms that compete with other companies in acquiring clients. Thus, we also analyze the research regarding search engines and interactions between clients, search engines, and companies. Finally, we examine the interactions of digital technologies with different contexts in terms of geography, confidentiality/privacy and security, regulation and piracy, as well as their implications in terms of digital marketing (contextual interactions). 
CONSIDERATIONS IN REGARDS TO THE PROTECTION OF PERSONAL RIGHTS

GRANTED AFTER THE PERSON'S DEATH

BIBLIOGRAPHY

1. Ansari, A., Essegaier, S., Kohli, R., Internet Recommendation Systems, Journal of Marketing Research

2. Berry, L. L. (2002), Relationship marketing. In Emerging Perspectives on Services Marketing, American Marketing Association

3. Bruhn, M. (2003), Relationship Marketing. Management of Customer Relationships, Pearson Education Limited (Publishing House)

4. Caceres, R.C. and Paparoidamis, N.G. (2007), Service Quality, Relationship Satisfaction, Trust, Commitment and Business-to-Business Loyalty, European Journal of Marketing

5. Chatterjee, P. (2001), Online Re views - Do Consumers Use Them?, ACR 2001 Proceedings

6. Chen, Y., Wang, Q., \& Xie, J. (2011), Online social interactions: A natural experiment on word of mouth versus observational learning, Journal of Marketing Research

7. Dave Chaffey, Fiona Ellis-Chadwick (2016), Digital marketing, Pearson

8. Gerrard Macintosh (2007), Customer orientation, relationship quality, and relational benefits to the firm, Journal of Services Marketing

9. Godes, D. , ( 2005), The Firm's Management of Social Interactions , Marketing Letters

10. MacInnis , D. J. , (2011) , A Framework for Conceptual Contributions in Marketing , Journal of Marketing

11. Morgan, N.A. (2012), Marketing and Business Performance, Journal of the Academy of Marketing Science

12. Nelson Oly Ndubisi (2007), Relationship marketing and customer loyalty, Marketing Intelligence \& Planning

13. Senecal, S., Nantel, J., (2004), The influence of online product recommendations on consumers online choices, Journal of Retailing

14. Smith, T., ( 2009), Marketing communications: A brand narrative approach

15. Yadav M.S., (2010) , Marketing in Computer-Mediated Environments: Research Synthesis and New Directions, Journal of Marketing

16. Yadav, M.S., Pavlou, P.A., (2014), Marketing in Computer-Mediated Environments: Research Synthesis and New Directions, Journal of Marketing

17. https://www.algoodbody.com

18. https://gdpr-info.eu/issues/personal-data/ 